\title{
TRICUSPID ATRESIA
}

\author{
BY \\ JAMES W. BROWN, DONALD HEATH, ${ }^{*}$ THOMAS L. MORRIS, AND WILLIAM
WHITAKER
}

From the Regional Cardiovascular Centre, City General Hospital, and the University Department of Medicine, The Royal Hospital, Sheffield

Received August 28, 1955

Tricuspid atresia is an uncommon form of cardiovascular malformation which occurred as the primary lesion 16 times in Abbott's (1936) 1000 cases of congenital heart disease and in 5 per cent of 670 of Campbell's (1953) patients with cyanotic congenital heart disease. Although isolated cases, such as Hedinger's (1915) patient who was 56, have been described in adult life, most of the patients with this rare anomaly have been reported in infancy or early childhood: 9 of the 15 cases of Astley et al. (1953) were 2 years of age or under and the oldest was 11 years. The features of 8 patients with tricuspid atresia, 7 of whom were 3 years or over, and of one patient with congenital tricuspid stenosis, aged 13, are described in the present communication, where the clinical manifestations of the disease in older patients and its diagnosis by special investigation are discussed. In four of the patients who died (Cases 2, 3,5, and 8) an account is given of the pathological findings which are considered in relation to survival. In two of these (Cases 2 and 8 ) a histological examination of the small pulmonary vessels was made and the abnormal appearances found in Case 2 are described.

\section{Clinical Features}

Symptomatology. All 9 patients complained of breathlessness on exertion and, with the exception of Cases 4 and 8 , had suffered from frequent coughs and colds. Cyanosis had been noted from birth in all except Case 9. On exertion Cases 1 and 2 had chest pain and Cases 1 and 7 had dizziness. Only Cases 5 and 9 had squatted. Cases 1 and 6 complained of palpitation.

Signs. All the patients except Case 9 showed gross central cyanosis and finger clubbing. In Case 9 the central cyanosis and finger clubbing were slight. Apart from Case 1, where the apex beat was felt in the fifth left intercostal space in the anterior axillary line, there was no clinical evidence of cardiomegaly. On auscultation none of the patients had a diastolic murmur or clinical evidence of pulmonary hypertension. The other clinical features are shown in Table I.

Electrocardiography. Electrocardiograms were recorded in all except Case 8 in the present series. All the tracings showed left axis deviation and in Cases 2, 3, 5, 6, and 7 there was also evidence of clockwise rotation of the heart (Fig. 1 and 2). There were abnormally tall peaked $\mathbf{P}$ waves in lead II, taking the upper limit of normal to be $2.5 \mathrm{~mm}$. (Goldberger, 1953) in Cases 2 and 3 , and using the criteria of Sokolow and Lyon (1949), there are cardiographic evidences of left ventricular hypertrophy in Cases 1 and 2.

Radiological Examination. The radiological findings in this series were summarized in Table II; the postero-anterior teleradiograms of Cases 1, 3, 4, and 5 are reproduced in Fig. 3 and the left anterior oblique views of Cases 2 and 5 in Fig. 4.

* Leverhulme Research Scholar, Royal College of Physicians, London. 
TABLE I

Features of Nine Patients with Tricuspid Atresia

\begin{tabular}{|c|c|c|c|c|c|c|c|c|}
\hline \multirow[b]{2}{*}{ Case } & \multirow[b]{2}{*}{ Age } & \multirow[b]{2}{*}{ Sex } & \multirow{2}{*}{$\begin{array}{l}\text { Systemic blood } \\
\text { pressure in } \\
\text { arms } \\
(\mathrm{mm} . \mathrm{Hg})\end{array}$} & \multicolumn{2}{|c|}{ Ausculatory signs } & \multirow{2}{*}{$\begin{array}{l}\text { Character } \\
\text { of cardiac } \\
\text { impulse }\end{array}$} & \multirow{2}{*}{$\begin{array}{c}\text { Prominent } \\
\text { wave in jugular } \\
\text { venous pulse }\end{array}$} & \multirow{2}{*}{$\begin{array}{l}\text { Hæmoglobin } \\
\text { in grams per } \\
100 \mathrm{ml} \text {. }\end{array}$} \\
\hline & & & & $\begin{array}{l}\text { Mitral } \\
\text { area }\end{array}$ & $\begin{array}{l}\text { Pulmonary } \\
\text { area }\end{array}$ & & & \\
\hline 1 & 44 & $\mathrm{~F}$ & $100 / 60$ & SM & $\begin{array}{l}\text { SM } \\
\text { P2 loud and } \\
\text { single }\end{array}$ & Apical thrust & Systolic & $16 \cdot 1$ \\
\hline 2 & 7 & $\mathbf{M}$ & $105 / 85$ & SM & $\begin{array}{l}\text { SM } \\
\text { P2 inaudible }\end{array}$ & $\begin{array}{l}\text { Heave over } \\
\text { lower sternum }\end{array}$ & Presystolic & $20 \cdot 4$ \\
\hline 3 & 6 & $\mathbf{M}$ & - & SM & $\begin{array}{l}\mathrm{SM}^{*} \\
\text { P2 loud and } \\
\text { single }\end{array}$ & - & Presystolic & $19 \cdot 2$ \\
\hline 4 & 13 & $\mathbf{M}$ & $120 / 80$ & SM & $\begin{array}{l}\text { SM * } \\
\text { P2 loud and } \\
\text { just split }\end{array}$ & Apical thrust & Presystolic & $20 \cdot 0$ \\
\hline $5 \dagger$ & 13 & $\mathrm{~F}$ & $100 / 75$ & SM & $\begin{array}{l}\text { SM } \\
\text { P2 single }\end{array}$ & $\begin{array}{l}\text { Heave over } \\
\text { lower sternum }\end{array}$ & Presystolic & $18 \cdot 5$ \\
\hline $6 \dagger$ & 3 & $\mathrm{~F}$ & - & - & $\begin{array}{l}\text { P2 loud and } \\
\text { just split }\end{array}$ & - & - & $13 \cdot 0$ \\
\hline 7 & 3 & $F$ & - & SM & $\begin{array}{l}\text { SM }^{*} \\
\text { P2 soft and } \\
\text { just split }\end{array}$ & $\begin{array}{l}\text { Heave over } \\
\text { lower sternum }\end{array}$ & - & $16 \cdot 1$ \\
\hline $8 \dagger$ & $\begin{array}{c}3 \\
\text { mo. }\end{array}$ & $F$ & - & SM & SM & - & - & - \\
\hline 9 & 6 & M & $115 / 80$ & SM & $\begin{array}{l}\text { SM } \\
\text { P2 single }\end{array}$ & Not diagnostic & Presystolic & $16 \cdot 1$ \\
\hline
\end{tabular}

* Associated thrill.

+ Case 5 was a mongol, Case 6 had a cleft palate, and Case 8 had congestive heart failure.

$\mathrm{SM}=$ Systolic murmur. The murmur was maximal at the base in all except Case 7 where it was maximal at the mitral area.

Angiocardiography. An angiocardiographic examination was carried out in 8 patients in the present series. In all except Case 5 the contrast medium passed within three seconds of injection from right to left atrium through an atrial septal defect and into the left ventricle (Fig. 5 and 6). These chambers appeared larger than normal. Left atrial filling was well seen in the lateral view within two seconds of injection. Although in Case 5 there was no early filling of the left atrium, the left ventricle was fully opacified in two seconds (Fig. 6) and even in the later films there was only slight opacification of the left atrium. These anomalous findings were explained by examination of the heart at necropsy and are further considered in the discussion. There was a characteristic clear area, called the "right ventricular window" by Campbell and Hills (1950), between the contrast medium in the right atrium and the left ventricle in all except Case 5. A small right ventricle opacified in this clear area except in Case 4 and this appeared to fill from the left ventricle (Fig. 5). The lateral angiocardiograms showed evidence of transposition in Case 4.

Cardiac Catheterization. This investigation was carried out in Cases 3 and 9. The catheter passed from the right atrium through an atrial septal defect into the left atrium. From this position the tip was directed into the left ventricle and the right and left pulmonary veins (Fig. 7). Blood samples for blood oxygen estimation were taken from the various sites entered by the tip of the catheter and intracardiac blood pressures were recorded (Fig. 8). In Case 3 the tip of the catheter 


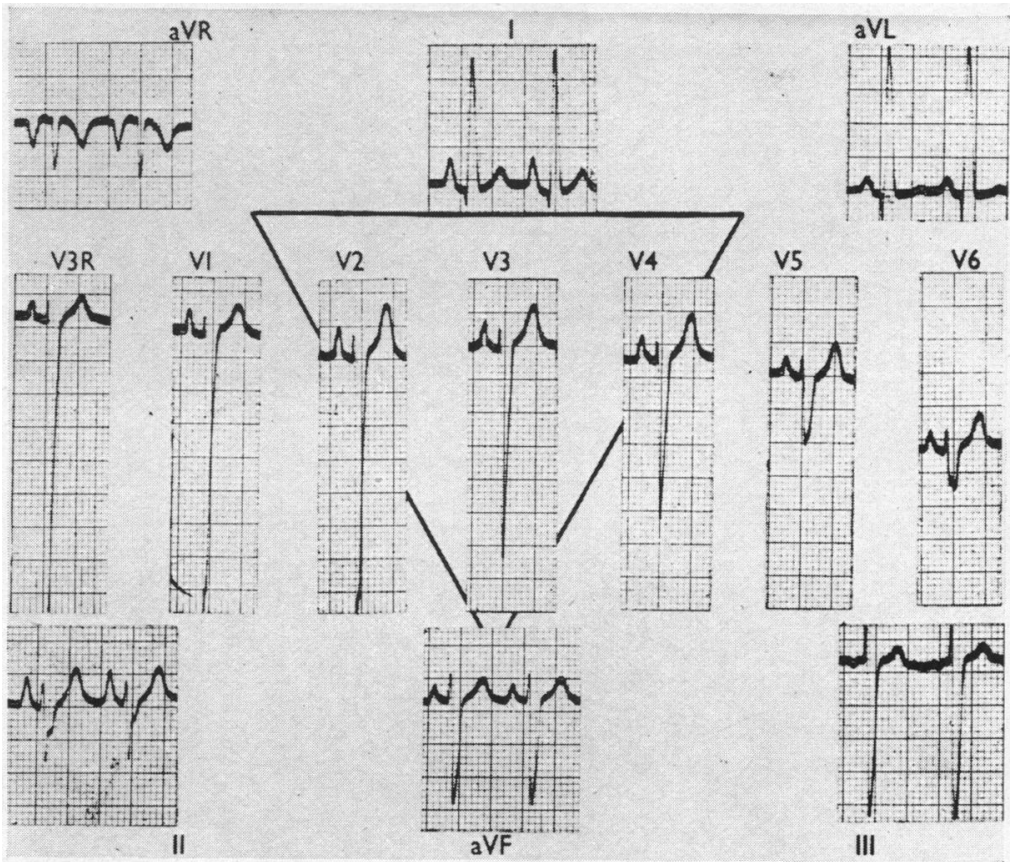

FIG. 1.-Electrocardiogram showing left axis deviation and peaked $\mathbf{P}$ waves. Case 3.

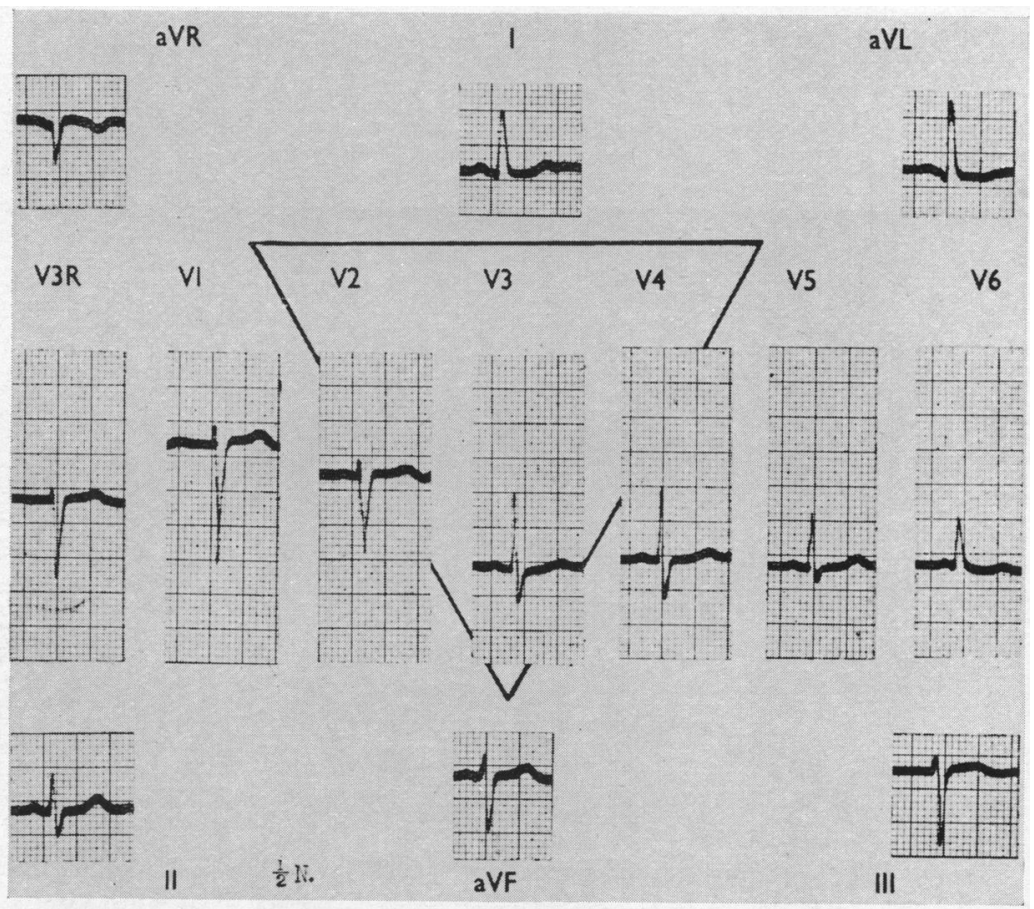

FIG. 2.-Electrocardiogram showing left axis deviation without peaked $\mathbf{P}$ waves. Case 4 . 


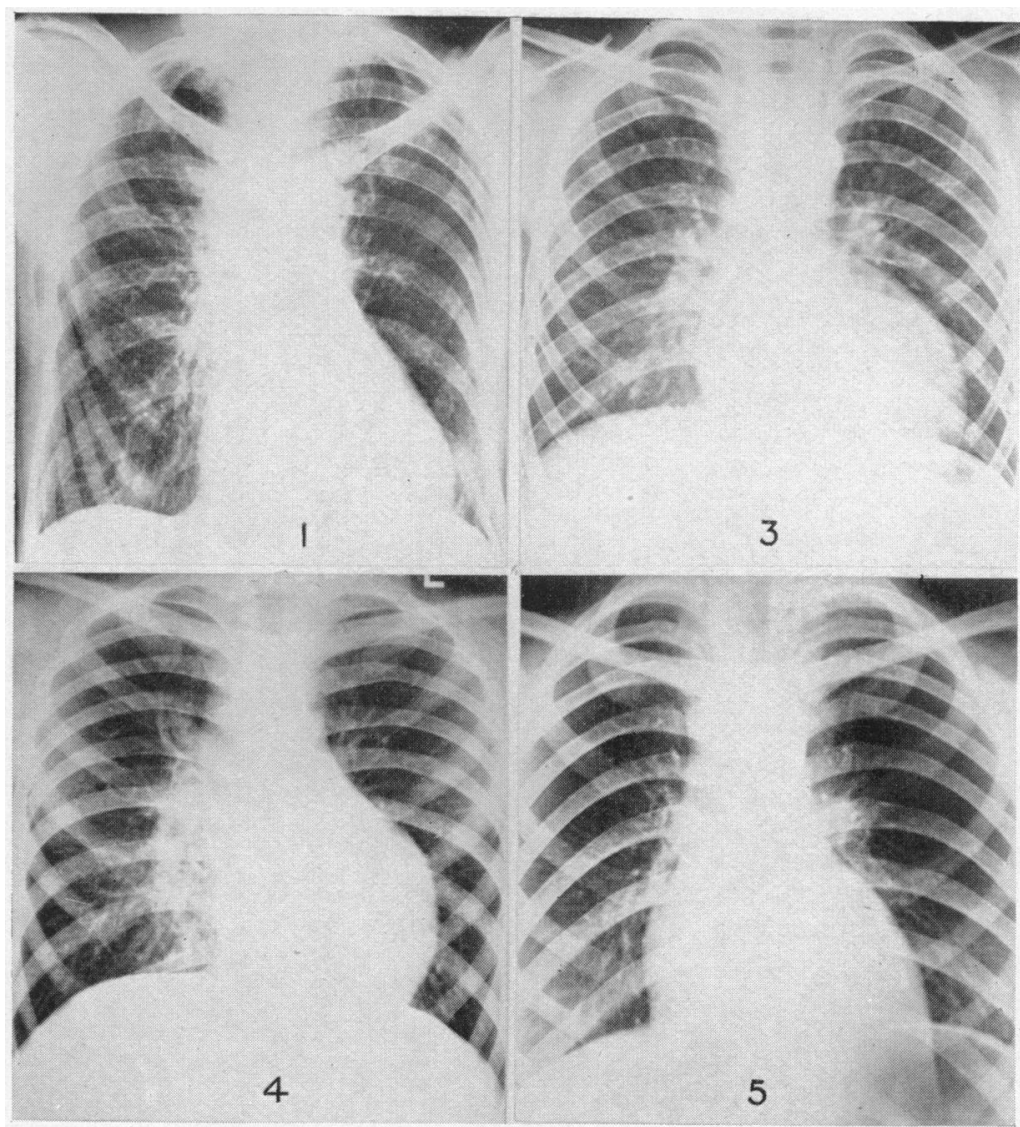

FIG. 3.-Postero-anterior teleradiograms of three patients with tricuspid atresia (Cases 1, 3, and 4) and one with congenital tricuspid stenosis. Case 5.

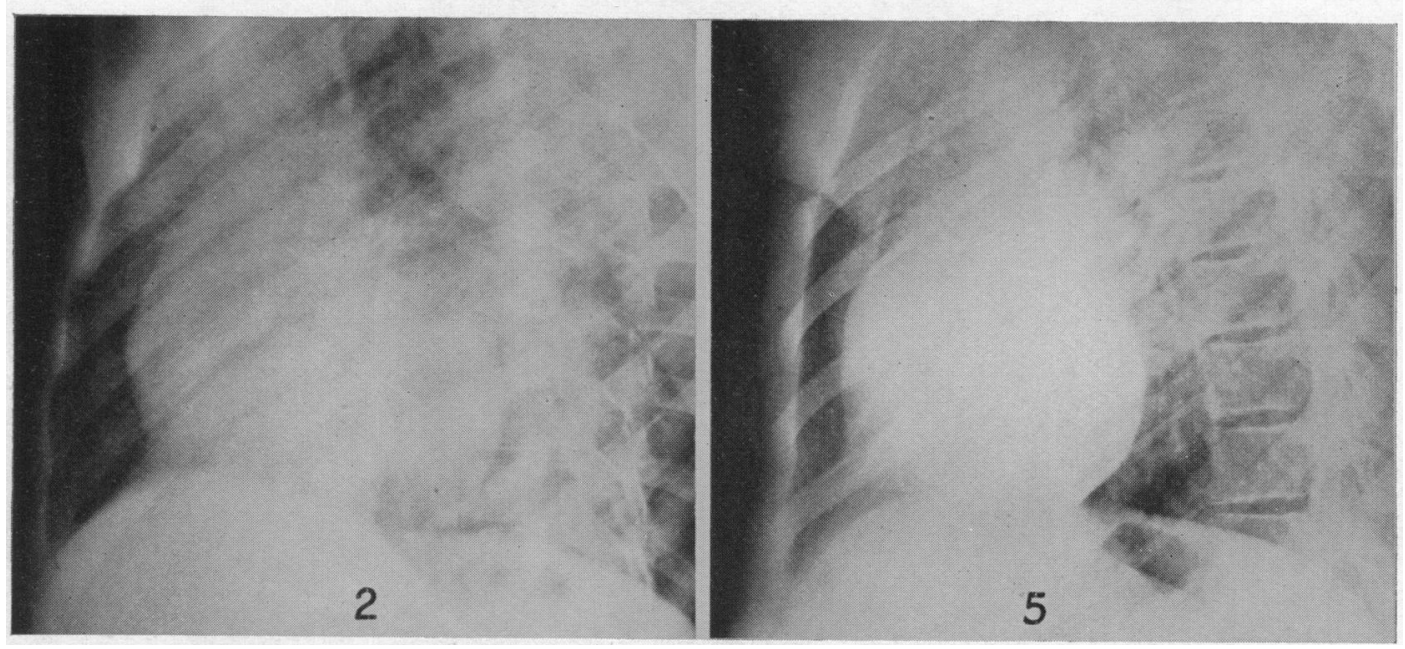

FIG. 4.-Left anterior oblique radiograms in Cases 2 and 5. Case 2 shows abnormal prominence of the posterior border, including the upper part, due to enlargement of the left ventricle and atrium, confirmed at autopsy. Case 5 shows no abnormal prominence of the posterior border although at autopsy the left ventricle was found to be large in this patient also. 


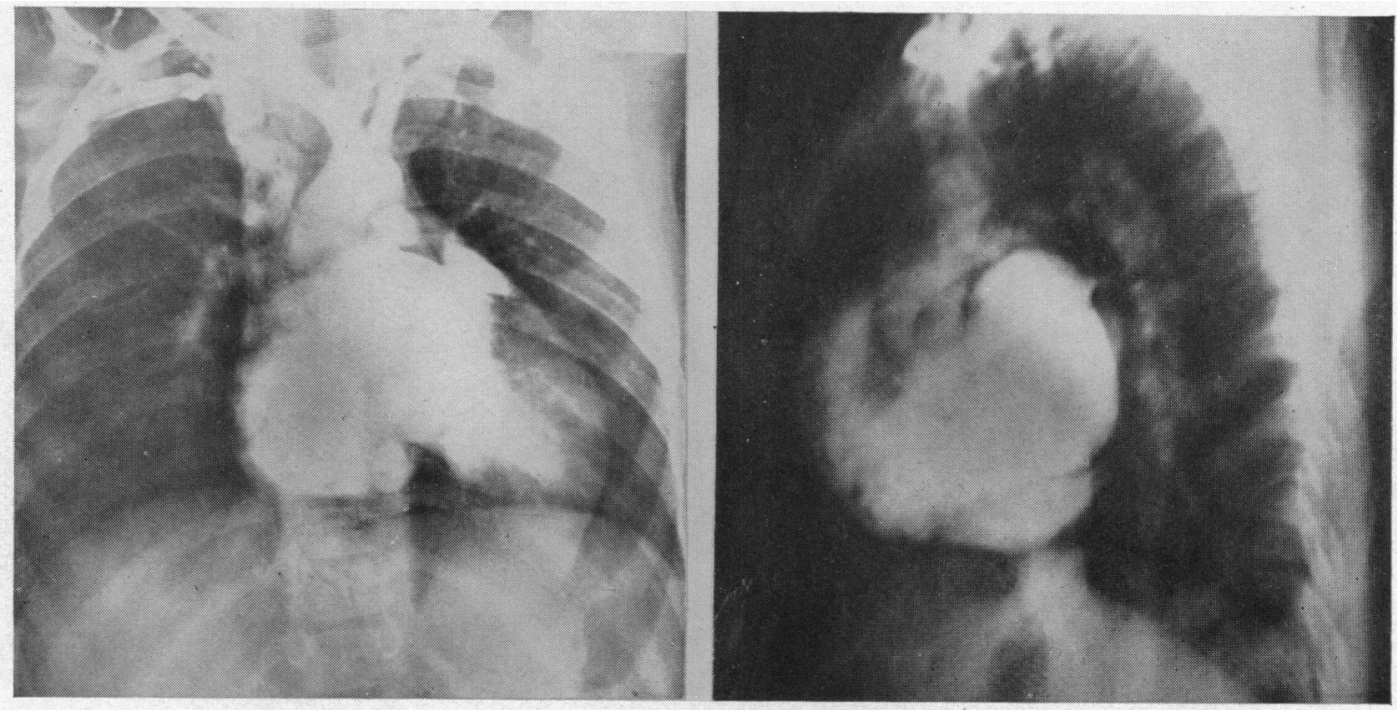

FIG. 5.-Postero-anterior and lateral angiograms at 2 seconds. The postero-anterior film shows early filling of the left atrium and a "ventricular window" with a diminutive right ventricle. The lateral film shows early filling of the left atrium and a normal origin of the great vessels. Case 2.

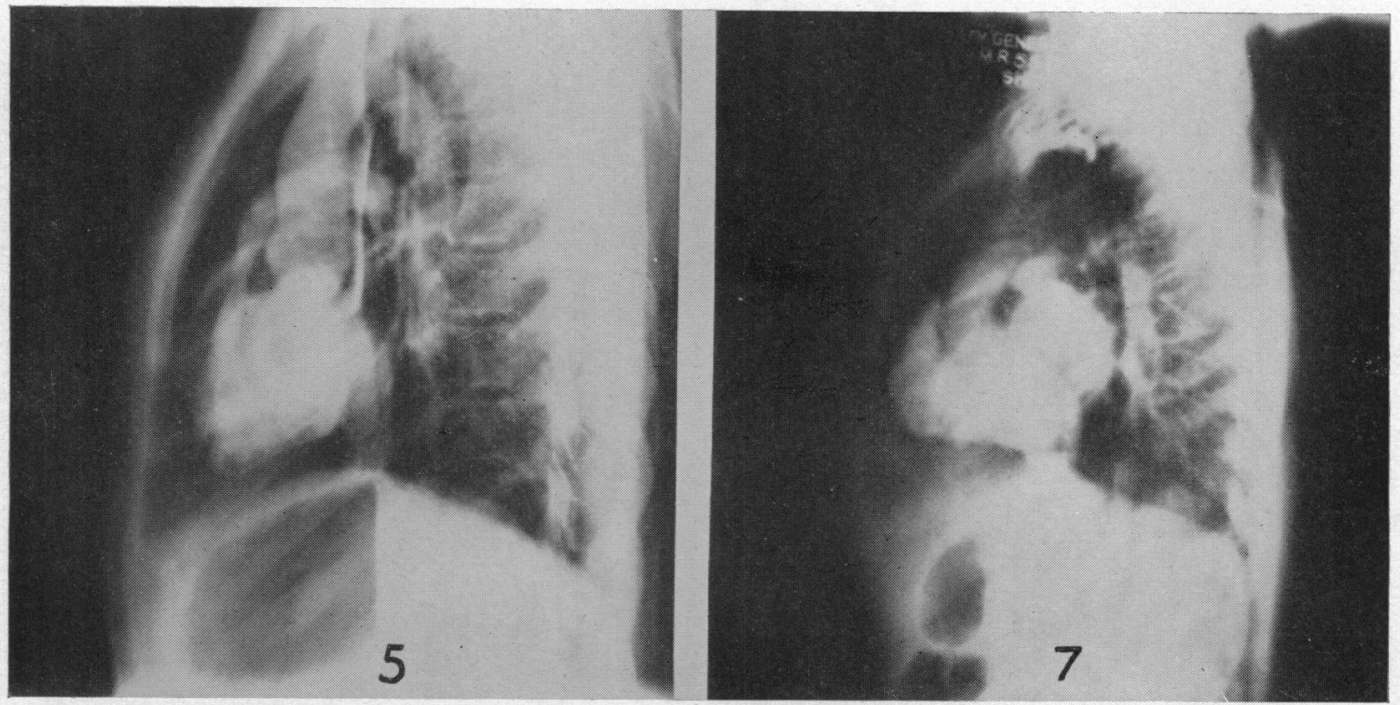

Fig. 6. - Lateral angiograms at 3 seconds. Case 7 shows early filling of the left atrium with contrast medium, whereas Case 5 does not. Hypoplasia of the pulmonary artery is well seen in Case 5. 
TABLE II

Radiological Findings in 8 Patients with Tricuspid Atresia

\begin{tabular}{|c|c|c|c|c|c|c|c|c|c|}
\hline \multicolumn{7}{|c|}{ Postero-anterior view } & \multicolumn{3}{|c|}{ Left anterior oblique view } \\
\hline $\begin{array}{c}\text { Case } \\
\text { No. }\end{array}$ & $\begin{array}{c}\text { Overall } \\
\text { cardiac } \\
\text { enlarge- } \\
\text { ment }\end{array}$ & Shape & $\begin{array}{c}\text { Concavity } \\
\text { of left } \\
\text { middle } \\
\text { segment }\end{array}$ & $\begin{array}{l}\text { Prominence } \\
\text { of main } \\
\text { branches of } \\
\text { pulmonary } \\
\text { artery }\end{array}$ & $\begin{array}{c}\text { Peripheral } \\
\text { pulmonary } \\
\text { vascu- } \\
\text { larity }\end{array}$ & $\begin{array}{l}\text { Prominence } \\
\text { of right } \\
\text { border of } \\
\text { heart }\end{array}$ & $\begin{array}{l}\text { Abnormal } \\
\text { prominence } \\
\text { of left } \\
\text { auricular } \\
\text { curve }\end{array}$ & $\begin{array}{l}\text { Abnormal } \\
\text { prominence } \\
\text { of left } \\
\text { ventricle }\end{array}$ & $\begin{array}{c}\text { Anterior } \\
\text { border }\end{array}$ \\
\hline 1 & $\mathbf{S}$ & Triangular & + & $\mathbf{N}$ & I & $\mathbf{N}$ & - & - & $\mathrm{C}$ \\
\hline 2 & $\mathbf{S}$ & Square & + & $\mathbf{N}$ & D & $\mathbf{F}$ & + & + & $\mathrm{C}$ \\
\hline 3 & $\mathbf{S}$ & Boot & + & $\mathbf{N}$ & D & $\mathrm{F}$ & $\cdots$ & + & $\ldots$ \\
\hline 4 & $\mathbf{S}$ & Square & + & I & I & D & - & - & $\mathrm{F}$ \\
\hline 5 & $\mathbf{S}$ & Bottle & + & D & D & $\mathbf{N}$ & - & - & $\mathrm{C}$ \\
\hline 6 & $\mathbf{S}$ & Normal & + & D & $\mathbf{N}$ & D & + & + & $\mathrm{C}$ \\
\hline 7 & $\mathbf{S}$ & Boot & + & I & I & $\mathbf{F}$ & + & + & $F$ \\
\hline 9 & $\mathrm{O}$ & Triangular & - & $\mathbf{N}$ & D & $\mathrm{F}$ & + & + & $\mathrm{C}$ \\
\hline
\end{tabular}

Key: $\mathrm{S}=$ slight. $\mathrm{O}=$ none. $\ldots$ =no observation made. $\mathrm{N}=$ normal. $\mathrm{I}=$ increased. $\mathrm{D}=$ diminished. $\mathrm{F}=$ flat. $\mathrm{C}=$ convex. $\quad+=$ present. $-=$ absent.

was re-inserted into the left upper pulmonary vein and contrast medium was injected which outlined the vessel (Fig. 7). The arterial blood oxygen saturation was measured in Case 1 and was 37 per cent.

\section{NECROPSY FINDINGS}

Necropsy examinations were carried out in Cases 2, 3, and 5 who died following anastomotic operations and in Case 8 who died with congestive cardiac failure.

Case 2. On opening the chest there were numerous anastomotic channels over the pericardium and mediastinal pleura. Only the left ventricle was visible judging by the extreme right-sided position of the anterior descending branch of the left coronary artery. On dissection of the heart the right atrium was dilated with a large right atrial appendage (Fig. 9). Its wall was $2 \mathrm{~mm}$. thick. There were four defects in the atrial septum, a large defect $10 \mathrm{~mm}$. in diameter in the region of the foramen ovale and three small defects immediately below this (Fig. 10). The left atrium was dilated and the mitral ring was wide. The left ventricle was dilated and hypertrophied, its wall being $15 \mathrm{~mm}$. thick $10 \mathrm{~mm}$. below the attachment of the mitral valve, which was normal in structure. The aorta was dilated but the aortic valve was normal; the aorta and pulmonary artery arose in their normal position. There was a diminutive right ventricle lying slit-like in the right wall of the left ventricle; its free wall was $2 \mathrm{~mm}$. thick and its cavity $15 \mathrm{~mm}$. long. There was a muscular ventricular septal defect. There was atresia of the tricuspid valve. The pulmonary artery was hypoplastic and the pulmonary valve had three delicate semilunar cusps. There was no atheroma of the pulmonary vascular tree. The ductus was obliterated.

Histology of the Small Pulmonary Vessels (Fig. 13). The elastic pulmonary arteries $(>1000 \mu)$ were normal. There was no medial necrosis or atheroma. The vasa vasorum in the adventitia of these vessels were normal. The muscular pulmonary arteries $(100-1000 \mu)$ were thin-walled and there was widespread thrombosis in these vessels throughout the lungs. They were filled with organizing thrombi which had disorganized the structure of the vessels so that it was difficult to 

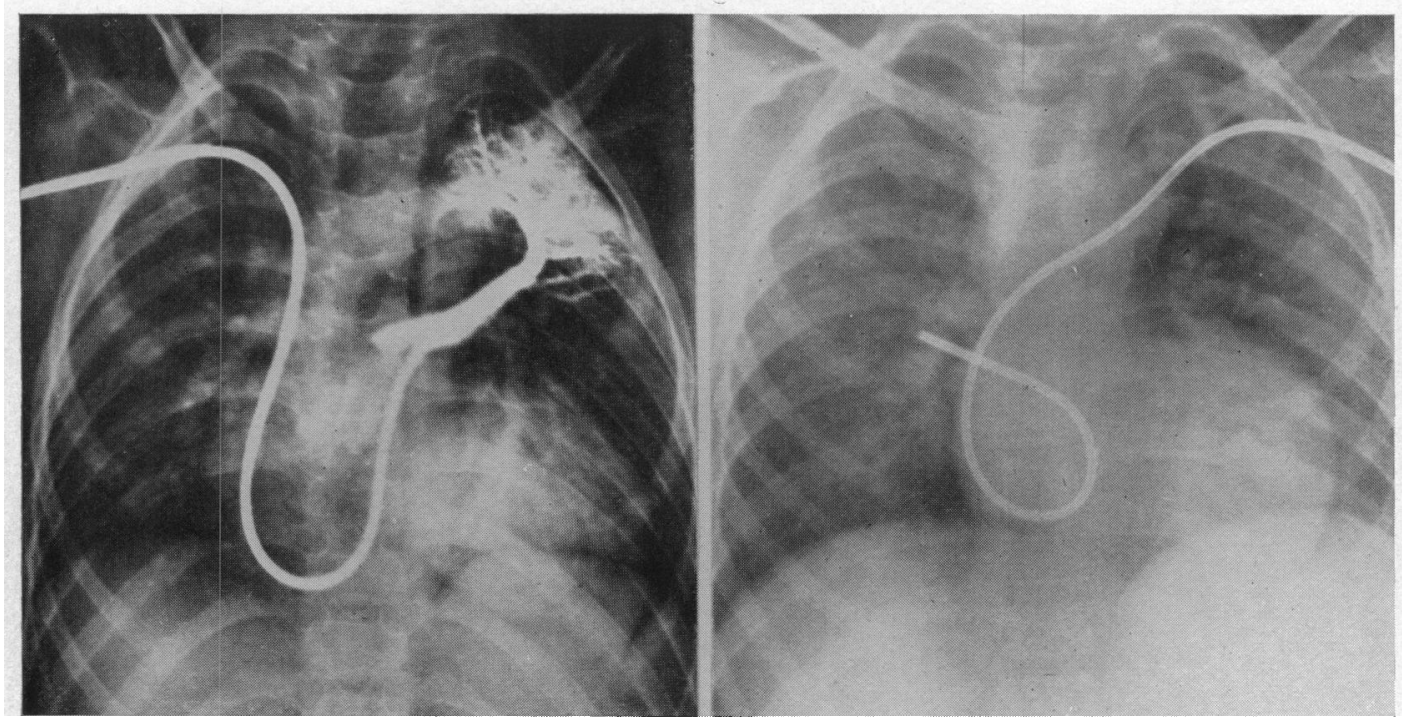

FIG. 7.-Films taken at cardiac catheterization. On the left the cardiac catheter has been passed through an atrial septal defect into a left upper pulmonary vein and contrast medium has been injected to outline the tributaries of this vein. On the right the cardiac catheter has been passed through an atrial septal defect into the right upper pulmonary vein. Case 3.

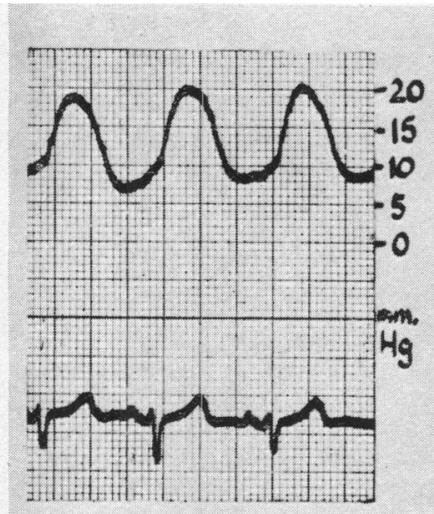

A.

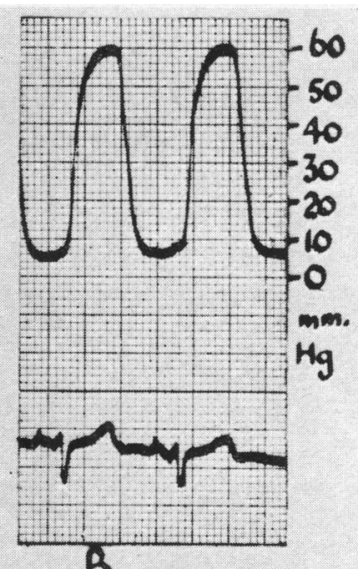

B.

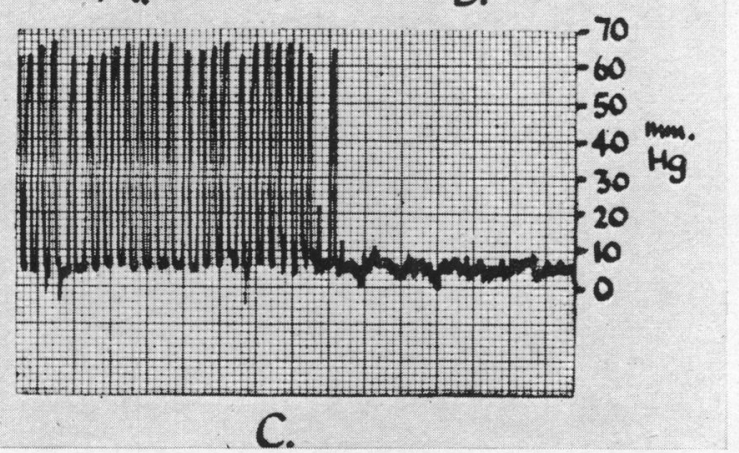

FiG. 8.-Blood pressure tracings taken at cardiac catheterization with the tip of the catheter in the right atrium (A), in the left ventricle (B), and being withdrawn from the left ventricle to the left atrium (C). Case 9. 


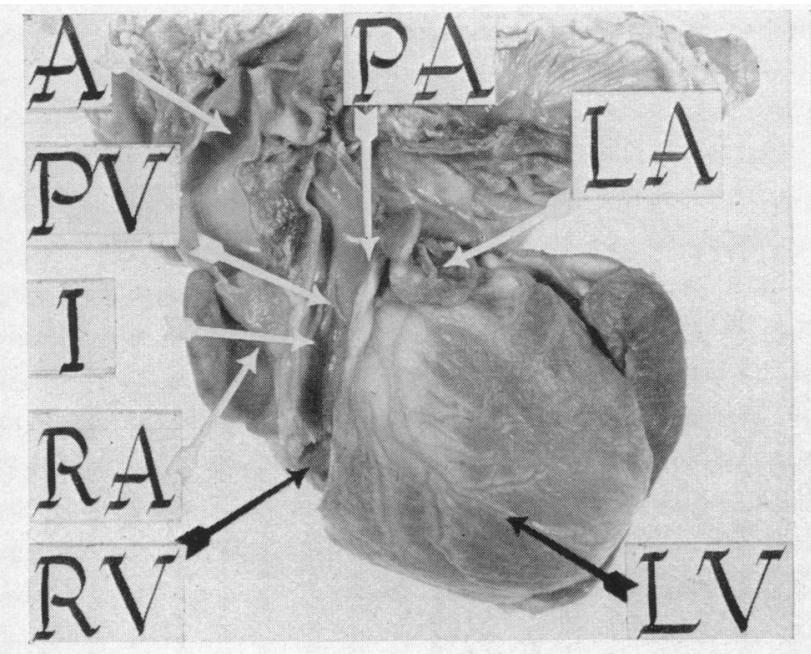

FIG. 9.-The heart has been dissected to show the small right ventricle lying in the wall of the hypertrophied left ventricle. Case 2 .

RA = Right atrium. $\quad$ PV $=$ Pulmonary valve. $\mathrm{LA}=$ Left atrium. PA $=$ Pulmonary artery. $\mathrm{RV}=$ Right ventricle. I=Infundibulum. $L V=$ Left ventricle. $\mathrm{A}=$ Aorta.

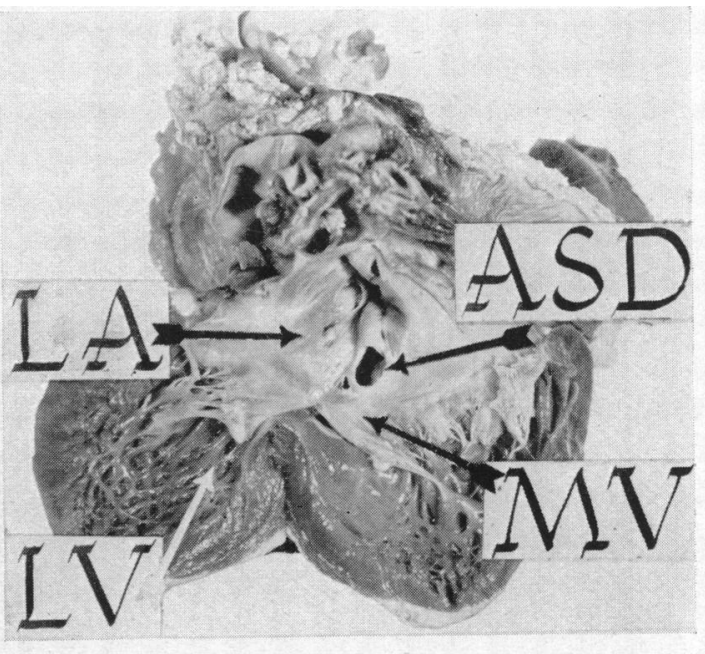

FIG. 10.-The left atrium and the left ventricle have been opened to show the wide mitral ring and the patent foramen ovale. Case 2 . $\mathrm{LA}=$ Left atrium. $\mathrm{MV}=$ Mitral valve. $L V=$ Left ventricle. ASD $=$ Atrial septal defect.

distinguish between arteries and veins. The pulmonary arterioles were thin-walled and showed extensive intravascular thrombosis. The visceral pleura was vascular, the layer of vascularity being about $300 \mu$ in depth and consisting of thin-walled vessels enmeshed by strands of fibrous tissue and elastic fibrils. Most of these vessels were $90 \times 30 \mu$ in diameter. There was no smooth muscle in the pleura. The lung parenchyma was unduly vascular, the increased vascularity being due to numerous dilated thin-walled vessels. Some of these were large, measuring about $600 \times 200 \mu$, but even the capillaries were dilated. On serial section, communications were demonstrated between the dilated vessels in the lung parenchyma and those in the vascular layer in the pleura but no anastomoses were shown between the vasa vasorum of the elastic arteries and the vessels of the lung parenchyma. The muscular pulmonary arteries gave off large dilated thin-walled branches. The intravascular thrombi were in various stages of organization and in most vessels there was multiple recanalization of old thrombus which gave a striking angiomatous appearance throughout the lung (Fig. 13). This appearance was produced by recanalization of thrombus and was not due to thin-walled collections of vessels such as are found in the lung in conditions producing bronchopulmonary anastomoses.

Case 3. The right atrium was large and in free communication with a dilated left atrium by means of an atrial septal defect $30 \mathrm{~mm}$. in diameter which occupied the upper half of the atrial septum. The left ventricle was dilated and hypertrophied, its wall being $14 \mathrm{~mm}$. thick just below the mitral valve, which was normal in structure. The mitral ring was dilated. The aorta was dilated with a normal aortic valve. There was no transposition of the great vessels. There was a diminutive right ventricle lying slit-like in the right wall of the left ventricle; its free wall $3 \mathrm{~mm}$. thick, its cavity $25 \mathrm{~mm}$. long. There was atresia of the tricuspid valve and there was a muscular ventricular septal defect.

Case 5. On superficial examination of the heart there appeared to be only a single ventricle, but on dissection a small right ventricle was found buried in the right wall of the dilated and hypertrophied left ventricle (Fig. 11). The cavity of the right ventricle was $50 \mathrm{~mm}$. long and the free wall of this chamber only $3 \mathrm{~mm}$. thick. The thickness of the left ventricular wall at the level of the insertion of the mitral valve was $10 \mathrm{~mm}$. The great vessels arose normally from the ventricles, 
the pulmonary artery was hypoplastic and free of atheromatous deposits. The pulmonary valve had three delicate semilunar cusps. There was a patent ductus arteriosus, $20 \mathrm{~mm}$. long and $10 \mathrm{~mm}$. in diameter. The right atrium was very large (Fig. 11) and since there was a persistent ostium primum it communicated freely with the hypertrophied left ventricle. The left atrium was small and received the pulmonary veins. There were three defects in the atrial septum the dimensions of which were $8 \times 5 \mathrm{~mm}$., $10 \times 8 \mathrm{~mm}$., and $4 \times 3 \mathrm{~mm}$. There was a small muscular ventricular septal defect (Fig. 12). There was stenosis of the tricuspid valve. The aorta was dilated but had three normal semilunar cusps. The free communication between the right atrium and the left ventricle due to the persistent ostium primum and the small atrial septal defects allowed blood to pass directly from the right atrium to the left ventricle rather than to the left atrium (Fig. 11). Since the persistent foramen primum provided a free communication from right atrium to left ventricle, the main flow of blood was probably in this direction rather than through the small atrial septal defect into the left atrium.

Case 8. The right atrium was enormous and its capacity appeared as great as the rest of the heart together. Its wall was $3 \mathrm{~mm}$. thick, and it communicated with a dilated left atrium through an atrial septal defect $30 \times 20 \mathrm{~mm}$. in size. The left ventricle was dilated and its wall was $12 \mathrm{~mm}$.

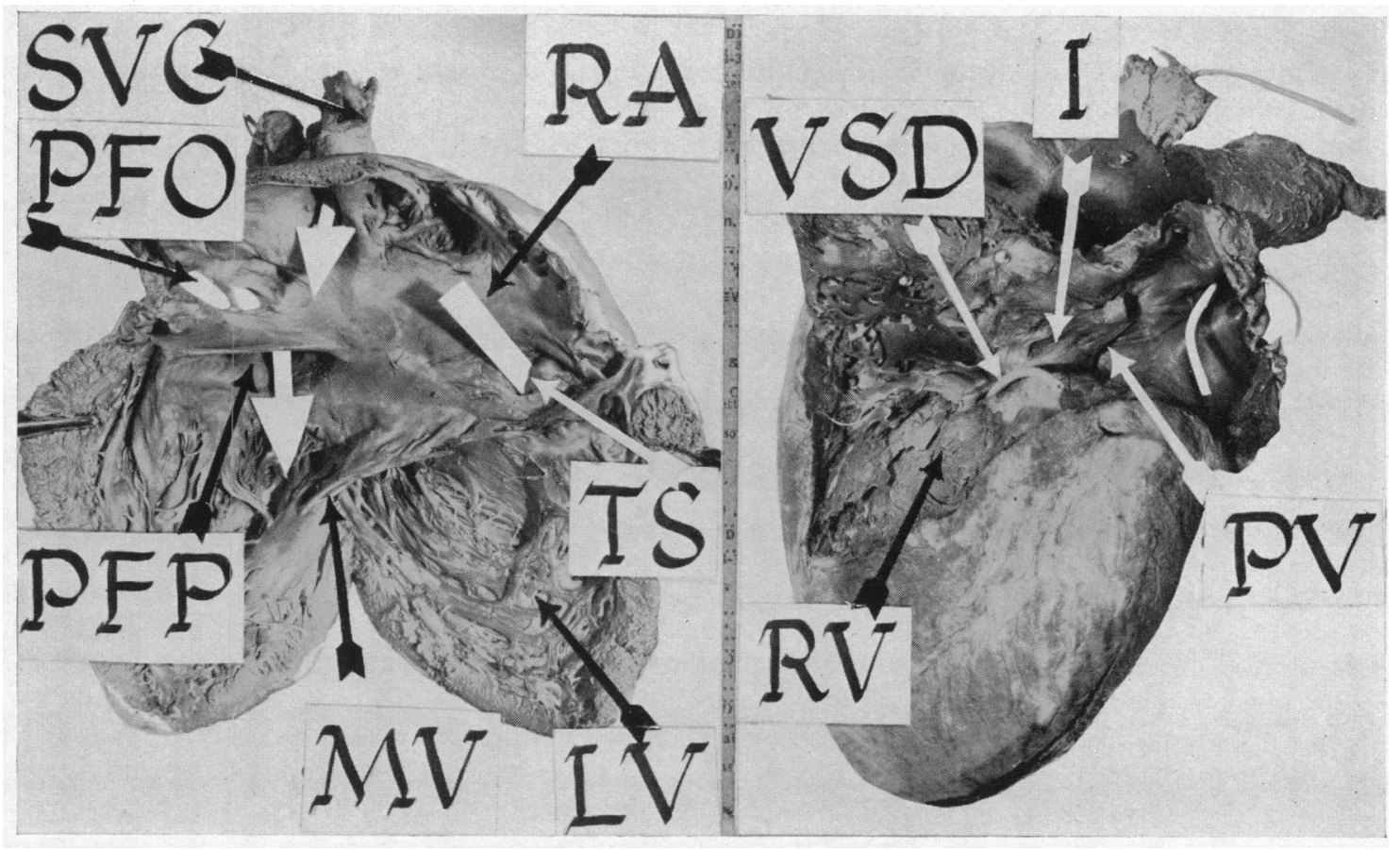

FIG. 11.-The left ventricle has been opened and the stenosed tricuspid orifice leading to a diminutive right ventricle has been marked by a rectangular white marker. The upper large white arrow indicates the direction of blood flow from the S.V.C. to the large right atrium and thence via a patent foramen primum into the left ventricle. The lower large white arrow indicates the direction of blood flow from the left atrium to the left ventricle. Two of the defects in the atrial septum in the region of the patent foramen ovale can be seen. Case 5.

SVC $=$ Superior vena cava. $\mathbf{P F O}=$ Patent foramen ovale. $\quad T S=$ Tricuspid stenosis. $\quad P F P=$ Patent foramen primum. $L V=$ Left ventricle. $\quad R A=R i g h t$ atrium. $\mathrm{MV}=$ Mitral valve.
FIG. 12.-Heart dissected to show small right ventricle lying in the wall of the hypertrophied left ventricle. A grey indicator in the right ventricle shows the site of a muscular ventricular septal defect. A white indicator has been passed through a patent ductus arteriosus from the pulmonary artery into the aorta and a third through the superior vena cava. Case 5.

VSD $=$ Ventricular septal defect. $\quad R V=$ Right ventricle. I=Infundibulum. $\quad \mathrm{PV}=$ Pulmonary valve. 
thick $1 \mathrm{~mm}$. below the mitral valve. It communicated with a small thin-walled $(3 \mathrm{~mm}$. $)$ right ventricle by means of a membranous ventricular septal defect $5 \mathrm{~mm}$. in diameter. There was no transposition of the great vessels. The aortic, pulmonary, and mitral valves were normal.

\section{Discussion}

Symptomatology. There is no symptom that is specific or even particularly suggestive of tricuspid atresia and the usual presenting triad of central cyanosis, dyspnœa on exertion, and frequent chest infections is common to most forms of cyanotic congenital heart disease. Central cyanosis which is present from birth or infancy is usually gross. Case 9 in the present series was not considered abnormally blue by his parents and had only a slight degree of central cyanosis, but in the other patients the cyanosis was easily discernable. Exceptionally, cyanosis may be absent: Gasul et al. (1950) reported an acyanotic case of tricuspid atresia where death occurred at the age of five months, but it is probable that central cyanosis would have developed had this child lived longer. Dyspnœa on exertion occurred in all the present patients and has been described with great frequency in previous reports (Rogers et al., 1950; Kroop, 1951; Astley et al., 1953; and Edwards et al., 1954). Frequent coughs and colds, which occurred in 8 of our patients, have not been commonly described.

Other symptoms that occur in association with tricuspid atresia appear so infrequently as to be of little diagnostic importance. Cases 1 and 7 in the present series suffered from dizziness on exertion but none had the spontaneous attacks of unconsciousness reported by Astley et al. (1953).

Squatting, which is not a common feature of tricuspid atresia, occurred in only two of the present series, Cases 5 and 9, and one of the 15 cases reported by Astley et al. (1953).

Signs. Central cyanosis and a præcordial systolic murmur without evidence of associated pulmonary hypertension are the dominant signs of tricuspid atresia. These features are exceptionally constant and have been noted by Taussig (1947), Brown (1950), Sommers and Johnson (1951), Kroop (1951), Anderson and McKee (1952), Astley et al. (1953), Edwards et al. (1954), Edwards (1953), and Kaplan and Robinson (1954). However, they are not diagnostic of the anomaly since they occur in other forms of cyanotic congenital heart disease such as Fallot's tetralogy, Ebstein's disease, and pulmonary stenosis with reversal of flow through a septal defect.

In congenital tricuspid atresia and stenosis, systemic venous blood mixes with pulmonary venous blood either by passing through an atrial septal defect into the left atrium or directly into the left ventricle (Case 5). In either instance there is a complete admixture of systemic and pulmonary venous blood causing left ventricular and systemic arterial blood to be unsaturated with oxygen. The degree of arterial oxygen unsaturation varies from case to case according to the amount of blood passing to the lungs. The central cyanosis that is observed clinically depends upon the degree of oxygen unsaturation and polycythæmia. Where cyanosis is absent, as in the case reported by Gasul et al. (1950), or develops in infancy, as in the cases reported by Dustin-Henry and Dustin (1947) and Astley et al. (1953), it is unlikely that the arterial blood is ever fully saturated with oxygen and the late appearance of the cyanosis is most probably determined by the development of polycythæmia. In the present series all except Cases 6 and 8 had abnormally high hæmoglobin values (Table I).

Finger clubbing, which is usually associated with severe degrees of cyanotic congenital heart disease, was present in all our patients and is to be expected when a case of tricuspid atresia survives infancy (Rogers et al., 1950; Brown, 1950; Anderson and McKee, 1952; Astley et al., 1953; and Edwards, 1954).

The systolic murmur in tricuspid atresia is usually maximal over the base of the heart and may be accompanied by a thrill (Table I). It is usually heard better to the left of the sternum but may be maximal in the second right intercostal space or even in the mitral area as in Case 7 where it was accompanied by a thrill. The murmurs accompanied by thrills in the present series radiated widely over the whole chest and into the neck. No particular diagnostic significance was attached 
to this radiation which was most probably determined by the intensity of the murmur. In Case 6 and in a case reported by Rogers et al. (1950) no murmur was heard. Kroop (1951) noted a diastolic murmur in the pulmonary area as well as a systolic murmur. Taussig (1947) considered that the murmur in tricuspid atresia originated from the passage of blood through the atrial septal defect or through an associated patent ductus arteriosus while Brown (1950) pointed out that a ventricular septal defect might be responsible. Another possible cause of the systolic murmur is the blood flow through collateral bronchial blood vessels which may be found in association with tricuspid atresia (Cases 1 and 2). The passage of blood through such vessels may have been the cause of the diastolic murmur noted by Kroop (1951).

The presence of an abnormally prominent venous pulse in 6 of our patients is in accord with the observations of Astley et al. (1953) who agreed with Taussig (1947) that in infants with tricuspid atresia this abnormal venous pulsation was most easily detected on palpation of the liver. In the jugular veins the abnormal pulse appeared clinically presystolic in 5 patients in this series and systolic in the other (Table I). A jugular phlebogram confirmed a single systolic venous wave in Case 1 but in Case 3 demonstrated that the abnormal wave which had been interpreted clinically as a giant " a" wave was an " ac" wave (Fig. 14). Taussig (1947) suggested that the abnormally prominent jugular venous pulse in tricuspid atresia was due to vigorous contractions of the right atrium attempting to expel blood through a small atrial septal defect into the left atrium. Prominent systolic venous waves may be caused by regurgitation of blood from the left ventricle into

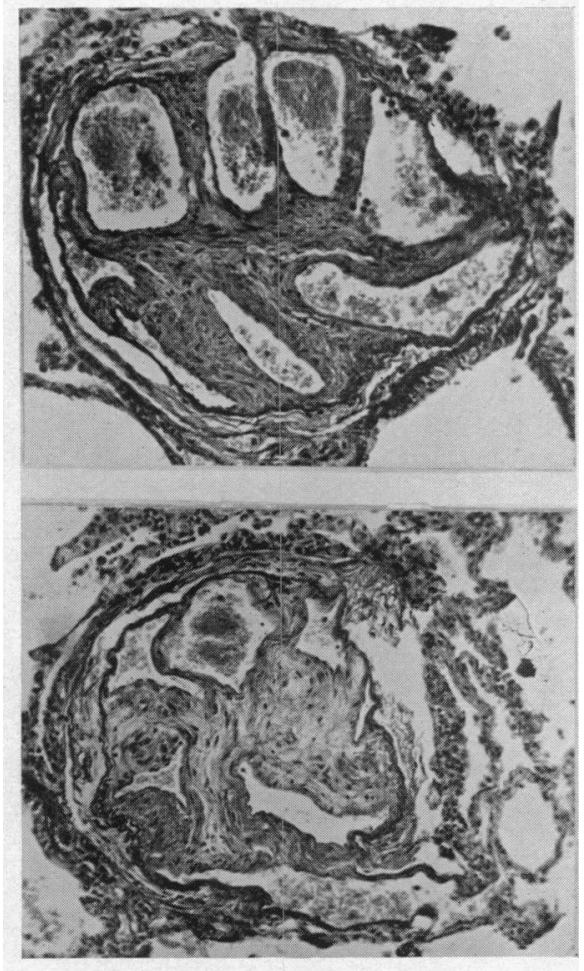

FIG. 13.-Transverse sections of two small pulmonary vessels, showing organized thrombus with multiple recanalization. It is impossible to identify these vessels as muscular pulmonary arteries or pulmonary veins. Verhœff/van Gieson stain. Magnification, $\times 180$. Case 2 .

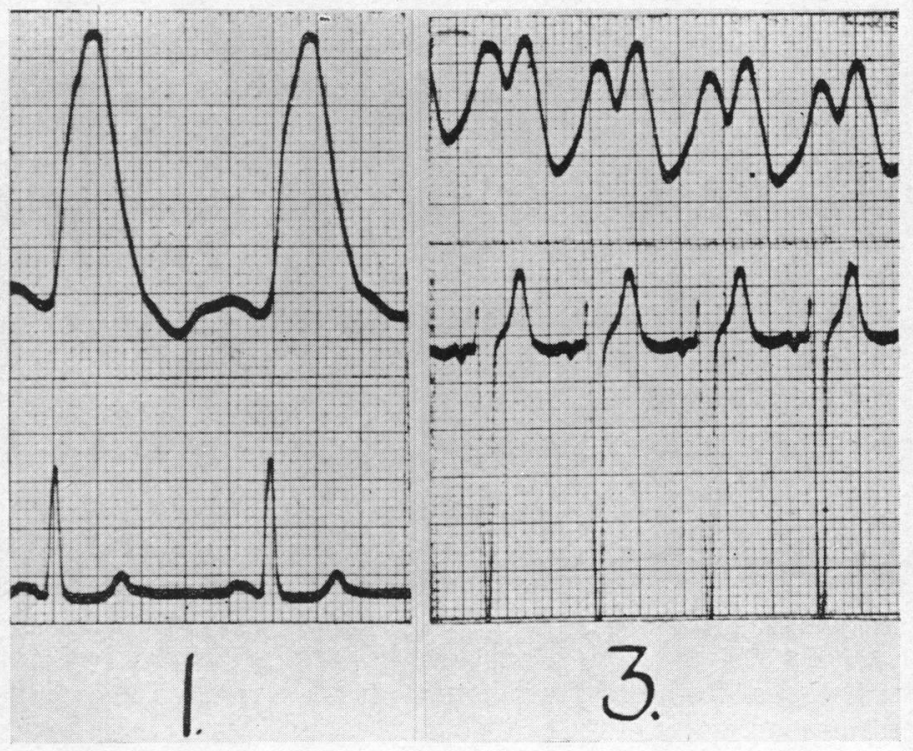

Fig. 14.-Synchronous records of the jugular phlebogram and the electrocardiogram. Case 1 shows single systolic venous waves. Case 3 shows $a c$ and $v$ waves. 
the right atrium through a wide mitral ring and a large atrial septal defect. The variety of jugular venous pulsations in the present patients suggests that there is no abnormal pulsation diagnostic of tricuspid atresia. The presence of an abnormal presystolic pulsation is not of great diagnostic value since giant "a" waves commonly occur in patients with other forms of congenital heart disease associated with either pulmonary hypertension or pulmonary stenosis.

Electrocardiography. Left axis deviation in the electrocardiogram is a characteristic but not pathognomonic feature of tricuspid atresia (Fig. 1 and 2). In a patient with cyanotic congenital heart disease this electrocardiographic sign suggests tricuspid atresia as the probable diagnosis. Left axis deviation was present in all the patients in this series but it is not invariably found in this anomaly and was absent in 2 of the 6 cases reported by Kroop and Grishman (1950) and 1 of the 15 cases reported by Kreutzer et al. (1954). A minor degree of right axis deviation was noted by Astley et al. (1953) in 1 of their 15 patients with tricuspid atresia. Left axis deviation occurs in other forms of cyanotic heart disease, such as persistent truncus arteriosus and common ventricle (Brown, 1950), complete transposition of the great vessels (Astley et al., 1953), congenital aortic atresia (Soloff, 1949), and infantile coarctation with cyanosis (Donzelot et al., 1950). It rarely occurs in Eisenmenger's complex (Astley et al., 1953; Bond, 1951; and Brown et al., 1955) and was noted by Astley et al. (1953) in a child with cyanosis due to methæmoglobinæmia.

Tall, peaked $P$ waves were regarded as a characteristic feature of tricuspid atresia by Kreutzer et al. (1954) and by Kroop and Grishman (1950). Although these authors thought that the P waves were peaked in all their cases they did not specify the height of the $P$ waves which they considered to be abnormal. In the present series only two patients having $P$ waves more than $2.5 \mathrm{~mm}$. in lead II were considered to show abnormally peaked $P$ waves according to the criteria defined by Goldberger (1953) (Fig. 1). This suggests that abnormally tall $\mathrm{P}$ waves are not such a common feature of tricuspid atresia as had been suggested by the previous authors and since peaked $P$ waves occur in other forms of cyanotic congenital heart disease such as Fallot's tetralogy, pulmonary stenosis and atresia, transposition of the great vessels, and Ebstein's disease they cannot be regarded of great diagnostic importance in tricuspid atresia. When they are present in tricuspid atresia they are probably due to hypertrophy of the right atrium, as in the other conditions. There was no heart block in cardiograms of the present patients but Astley et al. (1953) reported left bundlebranch block in one of their 15 patients and Dickson and Jones (1948) reported a case showing complete heart block.

\section{RADIOLOGY}

Astley et al. (1953) made a critical review of the radiological features of tricuspid atresia and concluded that it was often possible to diagnose the lesion from radiological examination. In the frontal projection a square-shaped heart, produced by concavity of the pulmonary segment and prominence of the upper part of the left lower segment below which the left cardiac border is vertical, was considered the most striking radiological feature. They thought that left ventricular hypertrophy might affect the upper part of the left lower segment of the cardiac border, but believed, from angiocardiographic evidence, that accentuation of this segment in patients with tricuspid atresia was due to prominence of the left atrial appendage. Four of the present patients showed a left atrial appendage on angiocardiography but only in Case 4 did it contribute to the square-shaped heart seen in the frontal projection (Fig. 3). Astley et al. (1953) pointed out also that this square-shaped configuration of the heart was rarely seen in Fallot's tetralogy, which is of great interest, since other authors have stressed the similarity of the radiological features of tricuspid atresia and the tetralogy of Fallot. Wittenborg et al. (1951) considered that 9 of their 11 patients with tricuspid atresia had a " cœur en sabot" resembling that of Fallot's tetralogy. Marder et al. (1953) stated that the cardiac silhouette in tricuspid atresia was rarely distinguishable from that of Fallot's tetralogy, while Soulié (1952) also commented on the similarity of the two conditions. Abrams and Alway (1951) thought that elevation of the cardiac apex was less striking with tricuspid atresia than with Fallot's tetralogy.

When the shape of the heart was examined in the frontal projection in the present series, none had more than a slight degree of cardiac enlargement; two, Cases 2 and 4, had square-shaped hearts; two, Cases 3 and 7, had a "cour en sabot"; two, Cases 1 and 9, had triangular-shaped hearts; one, Case 6, had a 
normal shaped heart, and in Case 5, with congenital tricuspid stenosis, the heart was bottle-shaped (Fig. 3, Table II). Since only 2 of the 9 patients in the present series and only 6 out of 15 reported by Astley et al. (1953) had square-shaped hearts the diagnostic importance of this feature should not be over-emphasized. When present, such a configuration is strongly suggestive of tricuspid atresia, but many patients with this lesion will have hearts of other shapes that are not diagnostic and probably indistinguishable from Fallot's tetralogy.

Concavity of the left middle segment of the cardiac border, which Astley et al. (1953) noted as a contributing feature to a square-shaped heart, has in itself been described as a characteristic feature of tricuspid atresia by Taussig (1947), Brown (1950), Rogers et al. (1950), Abrams and Alway (1951), Schnitker (1952) and Soulié (1952). Taussig (1947) considered that the concavity in the pulmonary segment was due to absence of the right ventricle but noted that it occurred in some cases of Fallot's tetralogy, transposition of the great vessels, and truncus arteriosus as well as tricuspid atresia. Although a concave pulmonary segment was observed in all except Case 9 in the present series (Fig. 3, Table II) this feature is not regarded as specifically diagnostic of tricuspid atresia but as a sign of hypoplasia of the right ventricle. Marder et al. (1953) stated that in patients with tricuspid atresia with transposition of the great vessels without pulmonary stenosis, the pulmonary arteries were enlarged and showed increased pulsation. Although in such cases, undue prominence rather than concavity of the pulmonary conus may be expected, the middle segment of the left cardiac border appeared concave in the postero-anterior teleradiogram in one patient in the present series, Case 4, where there was associated transposition of the great vessels without evidence of pulmonary stenosis. With the exception of Case 9, a concave left middle segment was noted in all patients in the present series, irrespective of cardiac shape.

Descriptions of the right cardiac border in tricuspid atresia have varied. Brown (1950), speaks of exaggerated convexity, Gasul et al. (1950) mention diminished projection of the right cardiac border, and Wittenborg et al. (1951) quote diminished convexity or actual concavity as characteristic of tricuspid atresia. Astley et al. (1953) observed only slight extension of the right cardiac border to the right of the spine in 11 of their 16 patients. In the present series of 9 patients the right heart border was less prominent than normal in 6 and was conspicuously flattened in 4 of these 6 (Table II). In view of the dilatation of the right atrium that occurs in tricuspid atresia this is unexpected. Wittenborg et al. (1951) believe that the diminished prominence of the right cardiac border is due directly to hypoplasia of the right ventricle, while Schnitker (1952) suggests that a large right atrium may not appear so because of the diminution in size of the right ventricle. Astley et al. (1953) observed a similar right cardiac border in 13 of 41 patients with the tetralogy of Fallot, and therefore considered that this feature was not of great diagnostic importance in tricuspid atresia. However, only 3 of a series of 20 patients with the tetralogy of Fallot studied in this unit showed diminished prominence of the right cardiac border and since this appearance was not observed in any of 8 cases of transposition of the great vessels, the frequency of this sign in tricuspid atresia suggests that it may be of diagnostic value, and being dependent upon a hypoplastic right ventricle is more likely to be found than some other radiological features that reflect anatomical abnormalities not always present.

According to Taussig (1947), the small size of the pulmonary artery is solely responsible for the narrow vascular pedicle, seen in both anteroposterior and left anterior oblique views, in tricuspid atresia. She believes that the narrow vascular pedicle associated with tricuspid atresia can be distinguished from that of the tetralogy of Fallot and of transposition of the great vessels. In Fallot's tetralogy the narrow pedicle is due to a combination of pulmonary artery hypoplasia and rotation of the great vessels, and in transposition of the great vessels to rotation alone; therefore, in both conditions the pedicle is normal or only slightly narrowed in the left anterior oblique view. Wittenborg et al. (1951) mentioned a narrow vascular pedicle as a sign characteristic of tricuspid atresia, but did not record its incidence in their series. Astley et al. (1953) found it in 8 of their 16 patients and in the present series 5 of the 8 cases examined radiologically had a narrow vascular pedicle in the frontal projection.

In the left anterior oblique position, prominence of the posterior border combined with diminished forward projection of the heart are signs usually regarded as evidence of a large left ventricle and a small right ventricle respectively, and were considered characteristic of tricuspid atresia by Taussig (1947) and Brown (1950). Astley et al. (1953) thought that a prominent upper part of the posterior border in this position, due to left atrial enlargement, was a more reliable feature of tricuspid atresia and stated that left atrial enlargement in a cyanosed patient should suggest tricuspid atresia.

Diminished projection of the anterior border was not accepted as evidence of a hypoplastic right ventricle by these authors who noted this appearance in the tetralogy of Fallot. Abrams and Alway (1951) also regarded this as a misleading sign and commented that, in congenital cardiac anomalies with right ventricular 
hypertrophy, the right ventricular shadow sometimes failed to project anterior to the aorta in the left anterior oblique position owing to the anterior position of the aorta. They also described a case of tricuspid atresia, with a hypoplastic right ventricle, where there was an abnormally prominent anterior projection in the left anterior oblique view due to a large right atrium. There was abnormal prominence of the posterior border in the left anterior oblique position in 5 patients in this series and in 4 of these (Fig. 4, Table II) the prominence involved the upper part of the posterior border. In 3 patients there was no abnormal prominence of the posterior border and in Case 5, where autopsy showed a very large left ventricle and a small left atrium, there was a wide margin between the heart shadow and the vertebral column. There was a straight anterior cardiac border in the left anterior oblique position in 2 patients in this series one of whom had transposition of the great vessels. The anterior cardiac outline was of the normal convex appearance and was not unduly displaced backward from the sternum in 5 cases (Table II). Examination of the heart in the left anterior oblique position may not help in diagnosis since, despite the considerable anatomical differences there may be identical appearances in patients with tricuspid atresia, Fallot's tetralogy, and transposition of the great vessels. Since a wide range of anomalies are associated with triscuspid atresia, there is no constant radiological appearance of the heart, but when present, a " square " heart and diminished projection of the right cardiac border in the frontal projection are useful diagnostic pointers.

The vascularity of the lungs has been commented on by many authors and Astley et al. (1953) considered that cases of tricuspid atresia could be divided into two distinct groups, those with normal or increased pulmonary vascularity and those with reduced pulmonary vascularity. Wittenborg et al. (1951) thought that increased vascularity, with or without hilar dance almost invariably indicated associated transposition of the great vessels. Kroop (1951) supported this interpretation of increased pulmonary vascularity but noted that the lung markings were not necessarily prominent when there was transposition without pulmonary stenosis, and that they might be normal when there was pulmonary stenosis, with or without transposition of the vessels. Astley et al. (1953) did not necessarily associate well-vascularized lungs with the presence of transposition of the great vessels as some of their patients with this complication had oligæmic lung fields. Their opinion is supported by the present series where only Case 4 of the three with increased pulmonary vascularity had transposition of the vessels. Case 1, the oldest in the present series, showed increased vascularity of the lungs from a dense collateral circulation.

Increased pulmonary vascularity contraindicates surgical treatment at any age. In infants it seems reasonable to assume, as Astley et al. (1953) have done, that pulmonary oligæmia is the most important criterion for surgical treatment but it should be borne in mind that the pulmonary artery may be too small to allow it to be anastomosed to another vessel.

\section{ANGIOCARDIOGRAPHY}

Angiocardiographic appearances that have been considered of diagnostic importance in tricuspid atresia are early filling of the left atrium through an atrial septal defect (Brown, 1950; Campbell and Hills, 1950; Denolin et al., 1950; Cooley et al., 1950; Soulié, 1952; Astley et al., 1953; Marder et al., 1953; Goodwin et al., 1953; and Fig. 5 and 6), a clear triangular area between right atrium and left ventricle (Campbell and Hills, 1950; Soulié, 1952; Marder et al., 1953; Astley et al., 1953; and Fig. 5) and opacification of a rudimentary right ventricle in the triangular clear area (Campbell and Hills, 1950; Astley et al., 1953; Goodwin et al., 1953; and Fig. 5).

Assessment of the early filling of the left atrium is more reliable using lateral angiocardiograms but filling can usually be recognized in the postero-anterior view particularly when there is opacification of the left auricular appendage (Fig. 5 and 6). The clear triangular area in the P-A angiocardiograms is due to absence of the right ventricular inflow tract. This sign, called " the right ventricular window" by Campbell and Hills (1950), was observed in all our 8 patients who had this investigation (Fig. 5). Early filling of the left atrium and a "right ventricular window" are angiocardiographic signs that must be present to support a diagnosis of tricuspid atresia, since patients with this anomaly will show early filling of the left atrium unless there is an associated persistent foramen primum which allows contrast medium to flow directly from the right atrium to the left ventricle as in Case 5 (Fig. 6).

Opacification of the rudimentary right ventricle in the right ventricular window provides confirmatory evidence of tricuspid atresia but this occurs only if there is a ventricular septal defect. 
Absence of this sign suggests there is not such a defect but does not contraindicate a diagnosis of tricuspid atresia. The patients in the present series, where this sign had been observed, who were examined at autopsy (Cases 2, 3, and 5) all had a ventricular septal defect (Fig. 12).

After it leaves the left ventricle the course of the contrast medium provides information of associated anatomical lesions and of the pulmonary vascularity. The origins of the great vessels are most clearly seen on the lateral angiocardiograms which allow associated transposition to be recognized (Fig. 5 and 6).

\section{CARDiac CATHETERIZATION}

Cardiac catheterization has rarely been carried out in the reported patients with tricuspid atresia. In Cases 3 and 9 in the present series where this investigation was performed, it was impossible to introduce the catheter into a right ventricle and the tip passed repeatedly through an atrial septal defect into the pulmonary veins and left ventricle (Fig. 7 and 8). Geraci et al. (1948) and Holling and Zak (1950) reported similar findings. Estimations of oxygen saturation of blood samples taken at cardiac catheterization showed that the pulmonary venous blood was normally saturated with oxygen and that there was mixing of the systemic and pulmonary venous bloods in the atria. Failure to enter the right ventricular cavity provides confirmatory evidence of tricuspid atresia although occasionally in other patients with large atrial septal defects it is difficult to direct the tip of the catheter through the tricuspid valve. There is usually no indication for cardiac catheterization where angiocardiography is available since this more often provides diagnostic evidence of tricuspid atresia.

\section{Discussion of PATHology}

Edwards and Burchell (1949) elaborated the classification of tricuspid atresia made by Kühne (1906) and defined the characteristic defects common to all varieties of the disease as atresia of the tricuspid orifice, patency of the atrial septum, usually a patent foramen ovale, and a large mitral orifice leading into a large left ventricle. In the present series Cases 2, 3, and 8 illustrate the features of Type $1 \mathrm{~b}$ tricuspid atresia defined by these authors. In Case 5 small deformed leaflets of the tricuspid valve were probe-patent and in addition there was a patent foramen primum which produced a common A-V canal. This latter abnormality is a common cardiac malformation in Mongolian idiocy which was present in Case 5.

(A) The classical features of uncomplicated tricuspid atresia. (Cases 2, 3, and 8; Fig. 9 and 10). All varieties of tricuspid atresia function as two-chambered hearts, one chamber consisting of the atria in communication with each other through a patent foramen ovale and the other consisting of the left ventricle. Venous blood from pulmonary and systemic circulation flows into the left atrium and thence through the mitral valve into the left ventricle and aorta. The abnormally high blood flow is associated with dilatation and hypertrophy of the left atrium, widening of the mitral ring, and hypertrophy of the left ventricle. There is usually no tricuspid orifice although in some cases bands of fibrous tissue replace the tricuspid valve which may be probe-patent (Case 5). Such cases of tricuspid stenosis are indistinguishable in life from tricuspid atresia.

Edwards and Burchell (1949) recognized four types of tricuspid atresia. In the first (Type 1a) there is pulmonary atresia as well as tricuspid atresia but no transposition of the great vessels or ventricular septal defect. The right ventricle is tiny and its cavity forms merely a slit in the hypertrophied wall of the left ventricle. Some cases of apparent single ventricle may be examples of tricuspid atresia in which the right ventricle is microscopic. The pulmonary artery is hypoplastic and the blood supply to the lungs is via a patent ductus arteriosus.

The second (Type 1b) is the commonest form of tricuspid atresia. Blood to the lungs is carried from a small but functioning right ventricle through a stenosed pulmonary valve to a hypoplastic but patent pulmonary artery. A ventricular septal defect allows the passage of blood from left to right ventricle. This was considered to be the anatomical arrangement in all except Case 4 in the present series (Fig. 9 and 10).

$2 \mathrm{~L}$ 
Transposition of the great vessels associated with stenosis of the right ventricular outflow tract occurs in the third type (Type 2a). There may be a pulmonary valvular or infundibular stenosis.

The fourth (Type $2 b$ ) is anatomically identical with the third form apart from the absence of pulmonary stenosis.

In the first three types of tricuspid atresia there is an anatomical barrier to the flow of blood to the lungs. In Type la the barrier of pulmonary atresia is absolute and blood must pass to the lungs through a patent ductus arteriosus or bronchial arteries. A ventricular septal defect and a hypoplastic pulmonary artery provide the resistance in Type $1 \mathrm{~b}$ while in Type $2 \mathrm{a}$ where the pulmonary artery arises from the left ventricle there is pulmonary or infundibular stenosis. These anatomical barriers lead to pulmonary hypotension and blood of high viscosity flows through the pulmonary vessels at low tension as in Fallot's tetralogy.

The fourth type of tricuspid atresia (Type $2 b$ ) is functionally quite distinct from the other three for blood flows at high pressure from the left ventricle to the lungs. The pulmonary arteries are subjected to pulmonary hypertension as in Eisenmenger's complex.

The striking histological changes described in Case 2 (who had Type $1 \mathrm{~b}$ tricuspid atresia (Fig. 13)), are probably related to the abnormal pulmonary circulation since anoxæmia, polycythæmia, and a slow blood flow are ideal conditions for the development of thrombi.

Similar histological appearances have been found in the lungs of patients with Fallot's tetralogy (Rich, 1948; Hales and Liebow, 1948) and would be expected in the lungs of patients with tricuspid atresia where there is also a sluggish blood flow; but not in Type $2 b$ where it is probable that the small pulmonary vessels would show features associated with pulmonary hypertension similar to those described in Eisenmenger's complex (Brown et al., 1955), patent ductus arteriosus with pulmonary hypertension (Whitaker et al., 1955), and ventricular septal defect with pulmonary hypertension (Heath et al., 1956).

(B) Features of tricuspid atresia complicated by persistent foramen primum. (Case 5; Fig. 11 and 12). Case 5 with congenital tricuspid stenosis had at autopsy features characteristic of tricuspid atresia, viz: tricuspid atresia, patent foramen ovale, a big left ventricle and a small right ventricle and in addition, a persistent foramen primum producing in this patient a common atrioventricular canal (Fig. 11). This additional lesion, which is common in mongols (Edwards et al., 1954) accounted for the angiocardiographic findings. The absence of left atrial filling was due to the contrast medium passing from the large right atrium into the left ventricle. The central cyanosis in Case 5 followed admixture of systemic and pulmonary venous blood in the left ventricle and not in the atria as in uncomplicated tricuspid atresia.

\section{PATHOGENESIS}

Various theories have been advanced to explain tricuspid atresia. An account has already been given by one of us (Brown, 1950) of the theory suggesting that the lesion results from unequal division of the common $\mathrm{A}-\mathrm{V}$ orifice by fusion and adhesion of the anterior and posterior cushions to the right wall. Chronologically such an event occurs at about the fourth week of intrauterine life. At this stage the anterior and posterior cushions of the atrial canal have fused except at their right and left extremities. These extremities are destined to become the right and left A-V ostia, and by thickening of the endocardium right and left endocardial cushions are formed from which develop the tricuspid and mitral valves. The developing interatrial septum joins with the middle part of the fused anterior and posterior cushions, and the developing inter-ventricular septum joins the right endocardial tubercule causing some narrowing of the right ostium. This is only temporary, for later the ventricular septum is rotated so that its anterior part comes to the right and its posterior part to the left. This rotation brings it into alignment with the atrial septum. It seems likely that in tricuspid atresia normal rotation of the ventricular septum fails, and the right ostium is compressed and finally obliterated. The associated ventricular septal defect is a true defect and represents failure of union between the bulbar septum and the ventricular septum owing to lack of rotation. Such a membranous ventricular septal defect was found in Case 8 . Similarly the 
frequent coincidence of pulmonary atresia or pulmonary conus stenosis suggests failure of torsion and unequal division of the bulbus and truncus. Tricuspid atresia has sometimes been ascribed to the effects of fœtal endocarditis, and occasionally a case may be seen in which there are rudimentary and fused valve leaflets as in Case 5. Much more often the site of a tricuspid valve is a smooth fibrous membrane, or trabecular muscular tissue in which no suggestion of valvular structure can be found. The occurrence of dextroposition or of complete transposition in many cases lends strength to a developmental origin.

Assuming the atresia to arise at about the fourth week, such abnormalities as the accompanying patent foramen ovale, persistent ostium secundum, patent ductus arteriosus, or hypoplasia of the pulmonary tract are really secondary abnormalities determined by the need of a circulation to the lungs on the one hand, and by altered dynamic changes in the blood flow on the other. The extent of these secondary defects determines whether the heart will function as a biloculate or triloculate heart.

Edwards (1953) believes that there is evidence against the view that tricuspid atresia is caused by an eccentric ventricular septum, for in cases of isolated pulmonary atresia, although the left ventricle is large, the right ventricle small, and the ventricular septum eccentric, tricuspid atresia need not be associated. Furthermore if tricuspid atresia were due to an eccentric ventricular septum, a membranous ventricular septal defect would always be expected due to failure of fusion of the ventricular and bulbar septa but in the present series 3 of the 4 cases (Cases 2, 3, and 5) had muscular defects.

\section{Differential Diagnosis}

Tricuspid atresia is most likely to be confused with Fallot's tetralogy but it must also be differentiated from the other forms of congenital heart disease that present with cyanosis without the signs of pulmonary hypertension. These include pulmonary stenosis with reversal of shunt through a septal defect, Ebstein's disease, some forms of transposition of the great vessels, some forms of persistent truncus arteriosus, and other more primitive types of congenital heart disease such as single ventricle, common atrio-ventricular canal, and biloculate and triloculate hearts. It is not possible to differentiate between tricuspid atresia and the more severe forms of congenital tricuspid stenosis associated with an atrial septal defect.

It seems probable that on clinical examination the majority of cases of tricuspid atresia will be diagnosed as suffering from Fallot's tetralogy. Occasionally, as in Cases 1 and 4 of the present series a left ventricular thrust at the apex may indicate the correct diagnosis. In our experience this is the only clinical sign that suggested a diagnosis of tricuspid atresia. Although Taussig (1947) and Astley et al. (1953) considered presystolic hepatic pulsation in infants and abnormal presystolic pulsation in the neck veins of diagnostic importance, the jugular venous pulse was of no value in differential diagnosis in the present series.

Five of the present patients had abnormally prominent presystolic waves in the jugular venous pulse (Table I, Fig. 14) but clinically these were in no way different from the abnormal pulsations seen in patients with pulmonary stenosis and reversal of shunt through a septal defect, or with forms of congenital heart disease associated with pulmonary hypertension.

Differentiation of tricuspid atresia from Fallot's tetralogy and other forms of cyanotic congenital heart disease not associated with pulmonary hypertension will generally depend on electrocardiographic and special investigations. Left axis deviation in the cardiogram which is almost invariable in tricuspid atresia will generally make this distinction. Rarely such conditions as persistent truncus, Ebstein's disease, and transposition of the great vessels may be associated with left axis deviation in the electrocardiogram and such anomalies can be distinguished from tricuspid atresia by angiocardiography. Early filling of the left atrium and a " right ventricular window" on angiocardiography are diagnostic of tricuspid atresia in the presence of left axis deviation in the cardiogram. In conditions associated with pulmonary stenosis and pulmonary hypertension where 
there is a reversal of shunt through an atrial septal defect the cardiogram shows right axis deviation and right ventricular hypertrophy. Patients with Ebstein's disease may have left axis deviation in the cardiogram and show early filling of the left atrium in the angiocardiograms but this anomaly will always be recognized by other characteristic clinical, cardiographic, and radiological features and by the enormous size of the right atrium in angiocardiograms (Brown et al., 1955a). Tricuspid atresia can easily be distinguished clinically from congenital anomalies associated with severe pulmonary hypertension such as Eisenmenger's complex, patent ductus arteriosus, ventricular and atrial septal defect associated with reversal of flow, and idiopathic pulmonary hypertension, by the absence of the classical clinical, cardiographic, and radiological signs of pulmonary hypertension which dominate this group of cases.

\section{Prognosis AND TREATMent}

The prognosis in tricuspid atresia is poor; Campbell and Deuchar (1953) pointed out that the mortality was higher in tricuspid atresia than in any other type of congenital heart disease except pulmonary atresia and transposition of the aorta and pulmonary trunk.

Astley et al. (1953) noted that many patients with tricuspid atresia die in the first few months of life. This high mortality in infancy is presumably due to the effect of closure of a patent ductus on the pulmonary blood flow and, as pointed out by Kroop (1951), is especially liable to occur in those children without transposition but with pulmonary stenosis. Edwards (1953) believes that cases of tricuspid atresia with a non-functioning right ventricle or with transposition of the great vessels and no pulmonary stenosis rarely survive infancy and that patients with no transposition of the great vessels, a ventricular septal defect and a small right ventricle have a slightly better prognosis. He also considers that patients with transposition of the great vessels and pulmonary stenosis may reach adult life, as did the often misquoted woman patient of Hedinger (1915) who lived to the age of 56. This opinion is not in complete agreement with that expressed by Astley et al. (1953) who thought that death was likely to occur in infancy in patients with oligæmic lungs and that the prognosis was much more favourable when a pulmonary artery of normal calibre was transposed to the left ventricle. Since the cases reported by Hedinger (1915) and Geraci et al. (1948), who survived to adult life, all had transposition of the great vessels and pulmonary stenosis, associated transposition appears to be of favourable prognostic importance when combined with pulmonary stenosis. Paradoxically, the oldest patient in the present series (Case 1), who is still alive at the age of 45 years, has hypoplasia of the pulmonary arteries and no transposition. However, the radiological and angiocardiographic findings in this patient suggested that she had a well-developed bronchial collateral circulation which presumably accounts for her survival. It is impossible from the present series to make any dogmatic statements on the influence of associated anomalies on survival, since three of the patients died after having an operation.

The high mortality in infants with tricuspid atresia and pulmonary stenosis without transposition has encouraged operative treatment. Campbell and Deuchar (1953) reported the results of surgical treatment in 7 cases of tricuspid atresia with a non-functioning right ventricle: 2 died within a year and the other 5 did well, 3 of these 5 remaining well three years after operation, including a patient aged 19. They considered that the results of operation in tricuspid atresia were in general not as good as Fallot's tetralogy but in 3 of their cases the improvement was just as great. They thought that the heart size was the best guide to whether a patient with tricuspid atresia was likely to maintain improvement after operation and that if the cardio-thoracic ratio was under 54 per cent a good result might last for several years, but if it was more than 60 per cent prognosis was less certain. They quoted a mortality of 26 per cent within six months of operation in a series reported by Taussig et al. (1951). Gasul et al. (1949) have apparently obtained successful anastomoses using Pott's operation in children with tricuspid atresia. Astley et al. (1953) suggested that operative treatment should be extended to all patients with tricuspid atresia and pulmonary 
stenosis, and thought that the demonstration of pulmonary oligæmia was the sole criterion necessary before advising thoracotomy if they were satisfied that the atrial septal defect was large enough to allow a good flow of blood from right to left. Our experience of surgical treatment in patients who would have been considered most suitable on the criteria suggested by these authors has been disastrous. All three patients (Cases 2, 3, and 5) succumbed rapidly soon after operation. Histological examination of the lungs in Case 2 showed extensive intravascular thromboses in the muscular pulmonary arteries and veins suggesting that the pulmonary vascular bed had not been able to accept the increased blood supply directed to it through the shunt (Fig. 13). We believe that if operation is to be effective it must be carried out before the changes in the small pulmonary vessels have had time to develop and is more likely to be successful when performed in infants. The pulmonary vascular bed in Case 8 who died from congestive cardiac failure at the age of three months was normal.

\section{SUMMARY}

Eight patients with congenital tricuspid atresia and one with congenital tricuspid stenosis are described, with an account of the autopsy findings in four of them.

Characteristic symptoms were breathlessness on exertion, cyanosis, and recurrent chest infections but these are not specific to tricuspid atresia. On physical examination, central cyanosis and finger clubbing occurred in all, and a præcordial systolic murmur in all but one. A palpable thrust at the apex indicated left ventricular hypertrophy in two patients but in the others the clinical signs were suggestive of Fallot's tetralogy. The jugular venous pulse, although abnormal in six, was not characteristic enough to be diagnostic.

The electrocardiogram was recorded in 8 patients and showed left axis deviation in all. This was considered a most important diagnostic feature since it excluded the diagnosis of Fallot's tetralogy and suggested the probability of tricuspid airesia. Abnormally tall $\mathrm{P}$ waves occurred in only two patients.

Radiological examination was suggestive of tricuspid atresia in only two of the patients who showed square-shaped hearts. Generally, in tricuspid atresia the cardiac silhouette will be compatible with a diagnosis of Fallot's tetralogy.

Angiocardiography provided confirmatory diagnostic evidence in 7 of the 8 patients in whom it was done. Early filling of the left ventricle and a " right ventricular window," sometimes showing a diminutive right ventricle later, are pathognomonic signs in the antero-posterior views. The origin of the great vessels was well seen in the lateral views and there was evidence of transposition in only one of the patients.

Cardiac catheterization was performed in two patients. It provided anatomical confirmation of an atrial septal defect and suggested tricuspid atresia from inability to introduce the catheter into the right ventricle. Generally it is an unnecessary diagnostic procedure.

Autopsy examination of the heart in three cases showed classical abnormalities of tricuspid atresia and in a fourth, who was a mongol, an associated patent foramen primum.

Histological examination of the small pulmonary vessels was normal in the youngest patient aged 3 months, but in another aged 7 years showed great reduction of the pulmonary vascular bed due to extensive thrombosis in pulmonary arteries and veins. These pathological changes offered an explanation of the failure of anastomotic operations in four of our patients. It is suggested that anastomotic operations are more likely to be successful when carried out in infancy before the secondary pulmonary vascular changes develop.

We would like to thank Miss E. K. Abbott, Consultant Radiologist, for facilities in the Department of Radiology, City General Hospital, Sheffield; Miss N. Hardy and Mr. C. Lambourne for technical assistance; members of the Photographic Department of the United Sheffield Hospitals for the illustrations, and Miss M. Middlebrook for secretarial assistance. 


\section{REFERENCES}

Abbott, M. E., (1936). Atlas of Congenital Heart Disease. New York.

Abrams, H. L., and Alway, R. H. (1951). Pediatrics, 7, 660.

Anderson, R. M., and McKee, E. E. (1952). Amer. Heart J., 43, 761.

Astley, R., Oldham, J. S., and Parsons, C. (1953). Brit. Heart J., 15, 287.

Bond, V. F. (1951). Amer. Heart J., 42, 424.

Brown, J. W. (1950). Congenital Heart Disease. 2nd ed., Staples Press, London.

- Heath, D., and Whitaker, W. (1955a). Amer. J. Med. In press.

,,$-- \quad-(1955 b)$. Brit. Heart J., 17, 273.

Campbell, M. (1953). Brit. Heart J., 15, 462.

and Deuchar, D. (1953). Brit. med. J., 1, 349.

-

Cooley, R. N., Sloan, R. D., Hanlon, C. R., and Bahnson, H. T. (1950). Radiology, 54, 848.

Denolin, H., Lequime, J., Goksel, F., and Pannier, R. (1950). Acta Cardiologica, 5, 400.

Dickson, R. W., and Jones, J. P. (1948). Amer. J. Dis. Child., 75, 81.

Donzelot, E., Durand, M., Metianu, C., and Vlad, P. (1950). Arch. Mal. Caur, $43,577$.

Dustin-Henry, M. J., and Dustin, P. (1947). Acta Cardiologica, 2, 175.

Edwards, J. E. (1953). Pathology of the Heart (Editor, Gould, S. E.). Thomas, Springfield, Illinois.

-, Dry, T. J., Parker, R. L., Burchell, H. B., Wood, E. H., and Bulbulian, A. H. (1954). Atlas of Congenital Anomalies of the Heart and Great Vessels. Blackwell Scientific Publications. Oxford. and Burchell, H. B. (1949). Med. Clin. N. Amer. 33, 1177.

Gasul, B. M., Fell, E. H., Marrelis, W., and Casas, R. (1950). Pediatrics, 6, 862.

Geraci, J. E., Dry, T. J., and Burchell, H. B., (1948). Proc. Staff. Meet. Mayo Clin., 23, 510.

Goldberger, E. (1953). Unipolar Lead Electrocardiography and Vectorcardiography. Henry Kimpton, London.

Goodwin, J. F., Steiner, R. E., Mounsey, J. P. D., MacGregor, A. G., and Wayne, E. J. (1953). Brit. J. Rad., 26, 161 .

Halec, M. R., and Liebow, A. A. (1948). Bull. Internat. Ass Med. Museums, 28, 1

Heath, D., Brown, J. W., and Whitaker, W. (1956). Brit. Heart J., 18, 1.

Hedinger, E. (1915). Zentralbl. allg. Path. path Anat., 26, 529.

Holling, H. E., and Zak, G. A. (1950). Brit. Heart J., 12, 153.

Kaplan, H. J., and Robinson, S. J. (1954). Congenital Heart Disease. New York.

Kreutzer, R., Caprile, J. A., Berre, G. G., and Becu, L. M. (1954). Arch. Mal. Caur, 47, 113.

Kroop, I. G., and Grishman, A. (1950). J. Pediat., 37, 231. (1951). Amer. Heart J., 41, 549.

Kühne, M. (1906). Jahrh. fr. Kinderh., 79, 320.

Marder, S. N., Scaman, W. B., and Scott, W. G. (1953). Radiology, 61, 174.

Rich, A. R., (1948). Bull. Johns Hopkins Hosp., 82, 389.

Rogers, H. M., Cordes, J. H., and Edwards, J. E. (1950). Amer. J. Dis. Child., 80, 427.

Schnitker, M. A. (1952). Congenital Anomalies of the Heart and Great Vessels. New York. Oxford University Press.

Sokolow, M., and Lyon, T. P. (1949). Amer. Heart J., 37, 161.

Soloff, L. A. (1949). Amer. Heart J., 37, 123.

Sommers, S. C., and Johnson, J. M. (1951). Amer. Heart J., 41, 130.

Soulié, P. (1952). Cardiopathies Congenitales. L'Expansion Scientifique Française.

Taussig, H. B. (1947). Congenital Malformations of the Heart. Commonwealth Fund, New York.

, King, J. T., Bauersfield, R., and Padvamati-Iyer, S. (1951). Trans. Ass. Amer. Phys., $64,67$.

Whitaker, W., Heath, D., and Brown, J. W. (1955). Brit. Heart J., 17, 121.

Wittenborg, M. H., Neuhauser, E. B. D., and Sprunt, W. H. (1951). Amer. J. Roentgenol., $66,712$. 